\title{
Editorial
}

\section{The Concept of Mental Pain}

\author{
Eliana Tossani \\ Laboratory of Psychosomatics and Clinimetrics, Department of Psychology, University of Bologna, Bologna, Italy
}

Mental pain is no less real than other types of pain related to parts of the body, but does not seem to get adequate attention. A major problem is the lack of agreement about its distinctive features, conceptualization and operational definition. I will examine some suggested descriptions of mental pain, its association with psychiatric disorders and grief, its assessment and the implications that research in this field may entail.

\section{Definition of Mental Pain}

In the literature, terms such as mental pain, psychic pain, psychological pain, emptiness, psychache, internal perturbation, and psychological quality of life have been used to refer to the same construct.

Bakan [1] observed that the individual feels psychological pain at the moment when he/she becomes separated from a significant other. From his perspective, pain is the awareness of a disruption in the person's tendency towards maintaining individual wholeness and social unity. Sandler [2,3] defined psychological pain as the affective state associated with discrepancy between ideal and actual perception of self. Baumeister [4] referred to mental pain indirectly in his theory on suicide. He viewed mental pain as an aversive state of high self-awareness of inadequacy. When negative outcomes fall far below one's standards of the ideal self and aspirations, and outcomes are attributed to the self, that person experiences mental pain. The basic emotion in mental pain is, thus, self-disappointment.

Shneidman [5] defined psychache as an acute state of intense psychological pain associated with feelings of guilt, anguish, fear, panic, angst, loneliness and helplessness. The primary source of severe psychache is frustrated psychological needs' [6]. Psychache is the mental pain of being perturbed [7]. Perturbation refers to one's inner turmoil, or being upset or mentally disturbed [7].

Bolger [8] defined emotional pain as a state of 'feeling broken' that involved the experience of being wounded, loss of self, disconnection, and critical awareness of one's more negative attributes.

Essential characteristics of emotional pain were described as a sense of loss or incompleteness of self and an awareness of one's own role in the experience of emotional pain [8].

Orbach et al. $[9,10]$ have defined mental pain as 'a wide range of subjective experiences characterized as a perception of negative changes in the self and its function that is accompanied by strong negative feelings'. Intense 'unbearable' mental (psychological) pain is defined as an emotionally based extremely aversive feeling which can

\section{KARGER}

Fax +4161306 1234

E-Mail karger@karger.ch

www.karger.com
(C) 2012 S. Karger AG, Basel

0033-3190/13/0822-0067\$38.00/0

Accessible online at: www.karger.com/pps
Eliana Tossani, $\mathrm{PhD}$

Department of Psychology, University of Bologna

Viale Berti Pichat 5

IT-40127 Bologna (Italy)

E-Mail eliana.tossani2@unibo.it 
be experienced as torment. It can be associated with a psychiatric disorder or with a severe emotional trauma such as the death of a child. Psychological pain has many metaphors borrowed from physical pain (e.g. heartache, broken heart).

\section{Borderlands with Suffering and Other Types of Pain}

The International Association for the Study of Pain [11] defined pain as 'an unpleasant sensory and emotional experience associated with actual or potential tissue damage, or described in terms of such damage'. The existence of many types of pain can be understood by the identification of four broad categories: nociception, perception of pain, suffering, and pain behaviors [12]. Loeser [13] underlined that 'suffering can be the result of pain, or it can be engendered by many other states, such as fear, anxiety, depression, hunger, fatigue, or loss of loved objects. Suffering exists only in the mind and the events that lead to suffering will differ from one patient to another. There are no physical examination clues or laboratory tests or imaging studies that reveal its presence. We must ask the patient and listen to his or her narrative to find suffering.

Frankl [14] viewed suffering as a form of emptiness due to loss of meaning in life, underlining that cause of psychological problems originates from existential frustration. He added that ' ... existential frustration is in itself neither pathological nor pathogenic. A person's concern, even his despair, over the worthwhileness of life is an existential distress but by no means a mental disease' (p. 123). The individual basic concern should not be to avoid pain or gain pleasure, but to see meaning in life [15]. Suffering terminates at the moment a meaning is found for it [16].

Saunders $[17,18]$ emphasized the connection between physical pain and mental suffering: 'If physical symptoms are alleviated then mental pain is often lifted also'.

This view has many similarities with Cassell's $[19,20]$ definition of suffering. According to Cassell [19], suffering can be defined as a state of severe distress associated with events that threaten the intactness of the person, that occurs when an impending destruction of the person is perceived. 'Suffering is experienced by persons, not merely by bodies, and has its source in challenges that threaten the intactness of the person as a complex social and psychological entity' [19]. Suffering alienates the sufferer from self and society [21], and may engender a 'crisis of meaning' [22] and a disintegration of hope [23]. The term 'suffering' contains nonphysical dimensions - social, psychological, cultural, spiritual - associated with being a person that are relatively unaddressed in medical training [24]. As Sensky [25] noted, the term 'suffering', however, may mean different things to different people. Expressions such as 'suffering from intense pain', 'suffering from a terminal illness' or even 'suffering a hangover' are indicative of these ambiguities.

The borderland between mental pain and pain referred to the body is also of difficult definition, since pain always involves a psychological component [26]. Engel [26, p. 45] defines pain 'as a psychological experience involving the concepts of injury and suffering, but not contingent on actual physical injury. The idea of injury as well as the need to suffer may lead to pain, just as may a real lesion or injury. Similarly, the need not to suffer or not to accept the fact that injury may render a "painful" injury painless.'

\section{Mental Pain and Depression}

Klein [27] developed a dimensional model of unipolar, endogenomorphic depression based on three specific neurobiologic factors: inhibited central pleasure, disinhibited central pain, and inhibited psychomotor facilitatory mechanisms. Inhibited central pleasure represents an inability to respond to positive internal and external stimuli and results in anhedonia, lowered self-esteem, and hopelessness. Disinhibited central pain can be described as 'psychic pain' and represents an overresponse to negative images and stimuli. Subjects feel unhappy, guilty, agitated, and experience painful ruminations. Finally, inhibited psychomotor facilitatory mechanism is synonymous with psychomotor retardation, decreased energy, and slowed thinking.

Carroll $[28,29]$ extended Klein's model to characterize mood states in bipolar disorder. His model included four neurobiologic components (consummatory reward, incentive reward, central pain, and psychomotor function). Central pain is increased in depression, as reflected by agitation, pathologic guilt and hopelessness. In the depressed phase, this system is seen as disinhibited; stimuli that were previously nonaversive are experienced as distressing. On this basis, the depressed patient perceives neutral events as catastrophic. Changes in self-image due to central pain dysregulation go beyond feelings of incompetence and devaluation. The depressed patient perceives himself/herself as bad, unworthy, and guilty. In manic patients, a disinhibition of central pleasure repre- 
sents an overresponse to positive images and stimuli, resulting in inflated self-esteem, grandiosity, increased enjoyment of the environment, excessive activity, intrusiveness, and unrealistic optimism about the future. Inhibited central pain, proposed to occur in mania, results in an inability to perceive the negative qualities of oneself and one's environment. Clinical symptoms include inflated self-esteem, elation, a disregard for the painful consequences of one's behavior, and overoptimism about the future.

Indeed, several psychopathologists [e.g. 30] have emphasized that the patients with endogenous depression may manifest a 'distinct quality' of dysphoric mood. This feature was recognized by early clinicians $[31,32]$ and was described as a uniquely aversive, anguished, or uncomfortable experience that is characterized by painful tension and torment [31].

The study of van Heeringen et al. [33] reported changes in brain functioning in association with mental pain in depressed patients. The results showed that levels of mental pain do not correlate with severity of depression but are associated with an increased risk of suicide. The severity of mental pain in these depressed patients was associated with changes in cerebral blood flow in areas of the brain that are involved in the processing of emotions. The observation that depressed individuals become suicidal when they perceive their emotional state as painful and incapable of change [34] suggests a strong and persisting emotional input at the prefrontal level. Even though the findings of van Heeringen et al. [33] indicate that dorsolateral hyperactivity is associated with increased levels of mental pain, the interpretation of this association needs further study.

\section{Mental Pain and Suicide}

Psychological pain is a common construct for understanding suicide [5, 9, 35-37]. Suicide risk is much higher when the general psychological and emotional pain reaches intolerable intensity [38], particularly in the context of major mood disorders [39]. Shneidman [5] considered psychache to be the main ingredient of suicide and reported that psychological pain may be correlated to the fact that, if suffering individuals could somehow stop consciousness and still live, they would opt for that solution [40]. Shneidman [41] further postulated that psychache is intolerable because it results from basic needs that have been thwarted. Suicide occurs when the psychache is deemed by that individual to be unbearable. It is an es- cape from intolerable suffering. Pain threshold and pain tolerance are highly and negatively correlated with personal distress in suicidal persons [42-44]. In nonsuicidal persons, intense mental pain is associated with high sensitivity to bodily pain. Conversely, among suicidal persons, intense mental anguish is associated with low sensitivity to bodily pain.

\section{Mental Pain and Other Psychiatric Disorders}

Patients with borderline personality disorder have a range of intense dysphoric affects, sometimes experienced as aversive tension, including rage, sorrow, shame, panic, terror, and chronic feelings of emptiness and loneliness. These individuals can be distinguished from other groups by the overall degree of their multifaceted emotional pain $[45,46]$. This emotional pain has been interpreted as a response attempting to adapt to repetitive traumatic experiences in childhood such as the loss of a parent, parental mental illness, witnessed violence, emotional, physical and sexual abuse [47]. Emotional pain is described as intense by women who suffer from borderline personality disorder, and has been associated with a high prevalence of reported childhood abuse [48].

Leibenluft et al. [49] conceptualized self-mutilation as a need to feel a real physical pain as opposed to just an emotional pain. However this conceptualization is not congruent with the consistent reports of no pain upon self-mutilation. It has also been suggested that deliberate self-harm provides physical stimulation (i.e., pain) sufficiently compelling to divert the individual's attention from painful emotional arousal; deliberate self-harm may serve to shift attentional focus away from emotional pain and toward physical pain [50].

Mental pain has also been examined in the setting of post-traumatic stress disorder. Avoidance has been postulated to involve strategic, effortful processes aimed at avoiding trauma stimuli, whereas numbing has been theorized to be a form of conditioned 'emotional analgesia' that results from exposure to uncontrollable and unpredictable aversive stimuli [51]. If an emotional pain site is 'anesthetized', it is difficult to recognize emotions, much less discriminate, describe, or regulate these emotions. In a study involving 85 veterans, Monson et al. [52] assessed the relationships among emotion content and process variables and post-traumatic stress disorder symptomatology with military-related trauma; they suggested that depression may be a secondary effect of numbing recognition rather than vice versa. 


\section{Grief}

Engel [53] underlined that grief is the characteristic response to the loss of a valued object, be it a loved person, a cherished possession, a job, status, home, country, an ideal, a part of the body, etc. Further, Engel pointed out that grief is a cause of mental pain, produces a variety of bodily and psychological symptoms and it interferes with our ability to function effectively. Indeed, the most prominent characteristic of grief is its painfulness [54]. The pain of depression is similar to grief as are other depressive symptoms such as low energy, inward turning, preoccupation, guilt, and self-criticism. However, grief is less often characterized by low self-esteem, pessimism, and hopelessness. Losses of resources, including health, material resources, territory, status, relationships or kin, cause comparable emotional pain. Kato and Mann [55] have suggested, for example, that the loss of a spouse is often conceptualized as a loss of the emotional, instrumental, and financial aspects of social support.

\section{Assessment of Mental Pain}

Several instruments have been developed to measure mental pain or related constructs.

The Psychological Pain Assessment Scale [5] was influenced in content and structure by the Thematic Apperception Test. It incorporates a written essay component and requires a trained operator to administer the test and interpret the results. It is reported to have modest validity $[56,57]$.

The Multiple Visual Analog Scale [58] consists of 23 Visual Analog Scale items based on the Carroll-Klein model of manic depressive illness. Each item is presented as a $100-\mathrm{mm}$ line visual analog scale, with appropriate anchor statements describing the manic and depressive extremes of each symptom. Of the 23 items, 7 represent each of the major dimensions of the Carroll-Klein model (consummatory reward, central pain, and psychomotor regulation) and 2 items represent incentive reward. Results from clinical studies demonstrated high test-retest reliability of the Multiple Visual Analog Scale in depressed subjects [59] and good concurrent validity [60].

The Psychache Scale [61] was based on Shneidman's [5] definition of psychache that was associated with suicidality (i.e., chronic, free-floating, non-situation-specific psychological pain caused by frustration of vital needs) but does not include items relevant to the intensity of psychological pain. The Psychache Scale is a 13item self-report scale used to assess psychache; items are coded on a 5-point Likert-type scale. Good construct validity and internal consistency have also been reported [62]. The Psychache Scale can successfully differentiate between suicide attempters and nonattempters [61].

The Orbach and Mikulincer Mental Pain Scale [9] consists of 44 self-rated items, and draws on a conceptualization of mental pain as a perception of negative feelings. The items of the Orbach and Mikulincer Mental Pain Scale are divided into 9 factors: (1) irreversibility, (2) loss of control, (3) narcissist wounds, (4) emotional flooding, (5) freezing, (6) self-estrangement, (7) confusion, (8) social distancing, and (9) emptiness. Subjects rate each item on a 5-point Likert scale, with higher values reflecting greater mental pain. The Orbach and Mikulincer Mental Pain Scale demonstrated high internal consistency and test-retest reliability [9] and strong association with suicidality [10].

The Mee-Bunney Psychological Pain Assessment Scale [63] is a 10-item self-rating inventory, where items uniformly used the term 'psychological pain' to measure intensity of the pain (ranging from none to unbearable) and frequency (ranging from never to always). The intent of this scale is to provide the clinician with a quick and reliable assessment of psychological pain in psychiatric and nonpsychiatric populations. The Mee-Bunney Psychological Pain Assessment Scale demonstrated convergent validity, known-groups validity and internal reliability. Moreover, major depressive episode subjects with elevated scores on the Mee-Bunney Psychological Pain Assessment Scale had higher suicidality ratings and had an increased likelihood of having a past history of suicide attempts [63].

Büchi et al. $[64,65]$ have devised a measure called the Pictorial Representation of Self-Measure which, in validation studies [65], behaves as expected of a measure of suffering and fits well with Cassell's conceptualization of suffering $[19,20]$. This measure does not rely on language skills and can be used to rapidly elicit patients' appraisals of their suffering [66].

All these scales contribute to quantifying mental pain. However, clinicians tend not to ask their patients about their mental pain or suffering [25] and the most widely used interview-based instruments seem to ignore this aspect. Clinimetrics offers important opportunities for assessing clinical phenomena such as mental pain $[67,68]$. Table 1 illustrates how information on mental pain can 
Table 1. Clinical assessment scale for mental pain (copyright Fava GA, Tossani E, 2012)

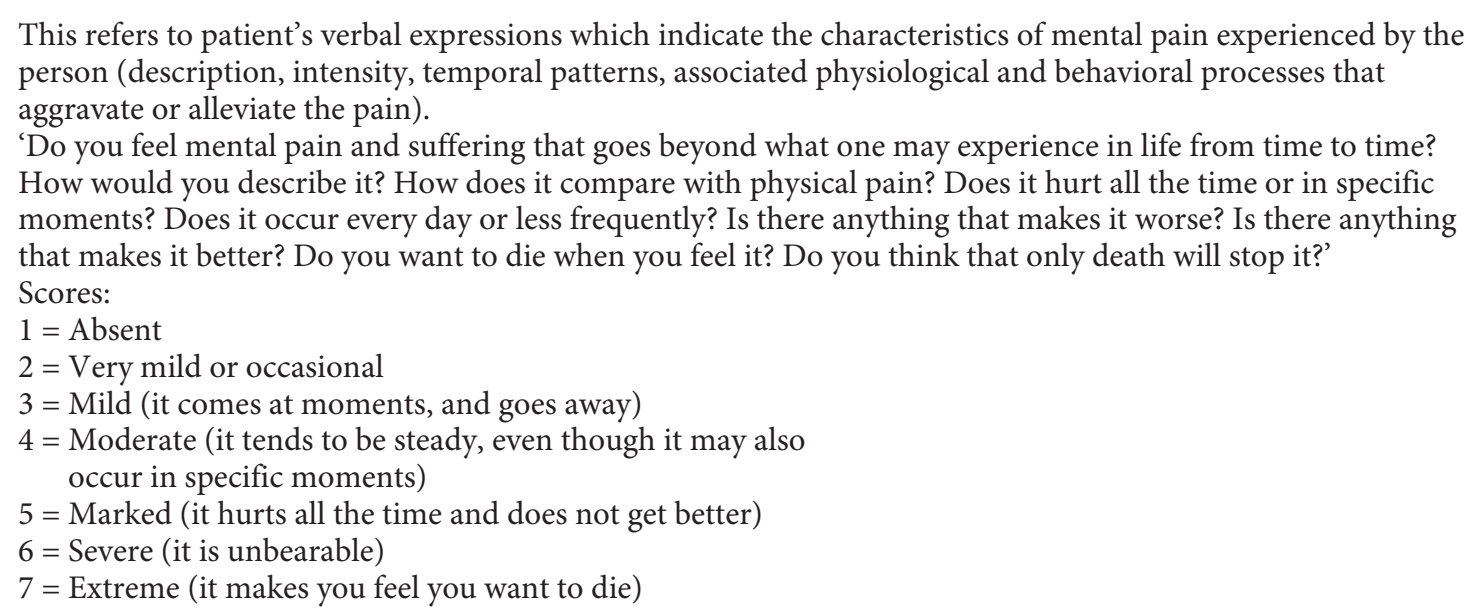

be obtained during an interview and can be rated. The format of the questions and ratings are modeled upon Paykel's Clinical Interview for Depression [69, 70], the most comprehensive and sensitive assessment tool for affective disorders.

\section{Clinical and Research Implications}

There is pressing need of research on mental pain, after decades of neglect. Some areas that appear to be particularly important are:

- even though mental pain always has an individual meaning, consensus should be developed on its operational definition;

- mental pain may provide the clinical threshold that is essential for determining the amount of distress that is worthy of clinical attention, in conjunction with diagnostic criteria. It may offer a better specification of the criterion on 'clinically significant distress' that frequently recurs in DSM-IV [34];

- the balance between mental pain and psychological well-being [71, 72] deserves attention. Engel [73], in his formulation of the pain-prone personality, outlined how, in some instances, somatic pain is clearly protecting the patient from more intense depression and even suicide, and the psychological profile of the need to suffer;

- the neurobiology of mental pain is a fascinating topic that has been addressed only by a very limited amount of research $[33,37,74,75]$. It may unravel the brain sys- tem that interprets the negative emotional significance of cognitions, with particular reference to the role of amygdala and basal ganglia [28].

- assessment of mental pain may have important implications in intervention research, particularly in psychopharmacology. For instance, depressed patients frequently report that treatment with antidepressant drugs yields substantial relief of their mental pain. Unfortunately, in psychopharmacology research the effects of drugs are measured on a limited range of symptoms [76].

Clinical and research attention to the issue of mental pain may produce important developments in psychiatry and is in line with recent emphasis on patient-reported outcomes, defined as any report coming directly from patients, without interpretation of physicians or others, about how they function or feel in relation to a health condition or its therapy [67].

\section{Acknowledgment}

I am very grateful to Professors Giovanni A. Fava and Tom Sensky for their invaluable help and comments. 


\section{References}

1 Bakan D: Disease, Pain, and Sacrifice: Toward a Psychology of Suffering. Chicago, Beacon Press, 1968.

$>2$ Sandler J: Psychology and psychoanalysis. Br J Med Psychol 1962;35:91-100.

3 Sandler J: Trauma, strain, and development; in Furst SS (ed): Psychic Trauma. New York, Basic Books, 1967, pp 154-174.

4 Baumeister RF: Suicide as escape from self. Psychol Rev 1990;97:90-113.

$>5$ Shneidman ES: Suicide as psychache. J Nerv Ment Dis 1993;181:145-147.

6 Shneidman ES: The Suicidal Mind. New York, Oxford University Press, 1998.

7 Shneidman ES: The psychological pain assessment scale. Suicide Life Threat Behav 1999;29:287-294.

$>8$ Bolger EA: Grounded theory analysis of emotional pain. Psychother Res 1999;9:342362.

9 Orbach I, Mikulincer M, Sirota P, GilboaSchechtman E: Mental pain: a multidimensional operationalization and definition. Suicide Life Threat Behav 2003;33:219-230.

10 Orbach I, Mikulincer M, Gilboa-Schechtman E, Sirota P: Mental pain and its relationship to suicidality and life meaning. Suicide Life Threat Behav 2003;33:231-241.

$>11$ International Association for the Study of Pain: Pain terms: a list with definitions and notes on usage. Recommended by the IASP Subcommittee on Taxonomy. Pain 1979;6: 249.

12 Loeser JD, Melzack R: Pain: an overview. Lancet 1999;353:1607-1069.

13 Loeser JD: Pain and suffering. Clin J Pain 2000;16:S2-S6.

14 Frankl VE: Man's Search for Meaning. New York, First Washington Square Press, 1963.

15 Frankl VE: Logotherapy and the challenge of suffering; in Hoeller K (ed): Readings in Existential Psychology and Psychiatry. Seattle, Review of Existential Psychology and Psychiatry, 1961, pp 63-67.

16 Frankl VE: Psychiatry and man's quest for meaning. J Relig Health 1962;1:93-103.

$\checkmark 17$ Saunders C: The treatment of intractable pain in terminal cancer. Proc Royal Soc Med 1963;56:195-197.

18 Saunders C: Distress in dying. BMJ 1963;2: 746.

19 Cassell EJ: The nature of suffering and the goals of medicine. N Engl J Med 1982;306: 639-645.

-20 Cassell EJ: Diagnosing suffering: a perspective. Ann Intern Med 1999;131:531-534.

21 Gillies J, Neimeyer RA: Loss, grief and the search for significance: towards a model of meaning reconstruction in bereavement. J Construct Psychol 2006;19:31-65.

-22 Barrett DA: Suffering and the process of transformation. I Pastoral Care 1999;53: 461-472.
23 Kearsley JH: The therapeutic use of self and the relief of suffering. Cancer Forum 2010; 34:98-101.

24 Egnew TR: Suffering, meaning, and healing: challenges of contemporary medicine. Ann Fam Med 2009;7:170-175.

25 Sensky T: Suffering. Int J Integr Care 2010; 10:66-68.

26 Engel GL: Pain; in Mac Bryde CM (ed): Signs and Symptoms. Applied Pathological Physiology and Clinical Interpretation. Philadelphia, Lippincott, 1969, pp 44-61.

27 Klein DF: Endogenomorphic depression: a conceptual and terminological revision. Arch Gen Psychiatry 1974;31:447.

28 Carroll BJ: Psychopathology and neurobiology of manic-depressive disorders; in Carroll BJ, Barrett JE (eds): Psychopathology and the Brain. New York, Raven Press, 1991, pp 265-285.

29 Carroll BJ: Brain mechanisms in manic depression. Clin Chem 1994;40:303-308.

30 Mendels J, Cochrane C: The nosology of depression: the endogenous-reactive concept. Am J Psychiatry 1968;124:1-11.

31 Kraepelin E: Manic-Depressive Insanity and Paranoia (transl Barclay RM).. Edinburgh, E\&S Livingstone, 1921.

32 Gillespie RD: Discussion on manic-depres sive psychosis. BMJ 1926;2:878-879.

33 van Heeringen K, Van den Abbeele D, Ver vaet $M$, Soenen L, Audenaert K: The functional neuroanatomy of mental pain in de pression. Psychiatry Res 2010;181:141-144.

34 American Psychiatric Association: Diagnostic and Statistical Manual of Mental Disorders, ed 4, Text Revision (DSM-IV-TR). Washington, American Psychiatric Press, 2000 .

35 Leenaars AA: Clinical evaluation of suicide risk. Psychiatry Clin Neurosci 1995;49:S61S68.

36 Valente SM: Messages of psychiatric patients who attempted or committed suicide. Clin Nurs Res 1994;3:316-333.

37 Mee S, Bunney BG, Reist C, Potkin SG, Bunney WE: Psychological pain: a review of evidence. J Psychiatr Res 2006;40:680-690.

38 Berlim MT, Mattevi BS, Pavanello DP, Caldieraro MA, Fleck MP, Wingate LR, Joiner TE: Psychache and suicidality in adult mood disordered outpatients in Brazil. Sui cide Life Threat Behav 2003;33:242-248.

39 Joiner TE Jr, Brown JS, Wingate LR: The psychology and neurobiology of suicidal behavior. Annu Rev Psychol 2005;56:287-314.

40 Shneidman ES: Aphorisms of suicide and some implications for psychotherapy. Am J Psychother 1984;38:319-328.

41 Shneidman ES: Definition of Suicide. New York, Wiley, 1985.

42 Orbach I, Palgi Y, Stein D, Har-Even D, Lotem-Peleg M, Asherov J, Elizur A: Tolerance of physical pain in suicidal individuals. Death Stud 1996;20:327-340.
43 Orbach I, Stein D, Palgi Y, Asherov J, HarEven D, Elizur A: Perception of physical pain in accident and suicide attempt patients: selfpreservation vs self-destruction. J Psychiatr Res 1996;30:307-320.

-44 Orbach I, Mikulincer M, Cohen D, King R, Stein D: Thresholds and tolerance of physical pain in suicidal and nonsuicidal adolescents. J Consult Clin Psychol 1997;65:646-652.

45 Zanarini MC, Frankenburg FR, DeLuca CJ, Hennen J, Khera GS, Gunderson JG: The pain of being borderline: dysphoric states specific to borderline personality disorder. Harv Rev Psychiatry 1998;6:201-207.

-46 Lieb K, Zanarini MC, Schmahl C, Linehan MM, Bohus M: Borderline personality disorder. Lancet 2004;364:453-461.

47 Goodwin JM: Redefining borderline syndromes as posttraumatic and rediscovering emotional containment as a first stage in treatment. J Interpers Violence 2005;20:20 25.

48 Meerwijk EL: We need to talk about psychological pain. Issues Ment Health Nurs 2012; 33:263-265.

49 Leibenluft E, Gardner DL, Cowdry RW: The inner experience of the borderline self-mutilator. J Pers Disord 1987;1:317-324.

50 Chapman AL, Gratz KL, Brown MZ: Solving the puzzle of deliberate self-harm: the experiential avoidance model. Behav Res Ther 2006;44:371-394.

51 Foa EB, Zinbarg R, Rothbaum BO: Uncontrollability and unpredictability in posttraumatic stress disorder: an animal model. Psychol Bull 1992;112:218-238.

52 Monson CM, Price JL, Rodriguez BF, Ripley MP, Warner RA: Emotional deficits in military-related PTSD: an investigation of content and process disturbances. J Trauma Stress 2004; 17:275-279.

53 Engel GL: Is grief a disease? Psychosom Med 1961;23:18-22.

54 Nesse RM: An evolutionary framework for understanding grief; in Carr D, Nesse R, Wortman CB (eds): Late Life Widowhood in the United States. New York, Springer, 2005, pp 195-226.

55 Kato PM, Mann T: A synthesis of psychological interventions for the bereaved. Clin Psychol Rev 1999;19:275-296.

56 Leenaars AA: A note on Schneidman's psychological pain assessment scale. OMEGA 2004;50:301-307.

57 Pompili M, Lester D, Leenaars A, Tatarelli R, Girardi P: Psychache and suicide: a preliminary investigation 2008;38:116-121.

58 Ahearn EP, Cassidy F, Kelley L, Weisler RH, Carroll BJ: Dimensions of self-rated mood in depressed, manic, and normal subjects. Compr Psychiatry 2001;42:196-201.

59 Ahearn EP, Carroll BJ: Short-term variability of mood ratings in unipolar and bipolar depressed patients. J Affect Disord 1996;36: 107-115. 
60 Ahearn EP, Cassidy F, Kelley L, Weisler RH, Carroll BJ: Dimensions of self-rated mood in depressed, manic, and normal subjects. Compr Psychiatry 2001;42:196-201.

-61 Holden R, Mehta K, Cunningham E, McLeod L: Development and preliminary validation of a scale of psychache. Can J Behav Sci 2001; 33:224-232.

-62 Mills JF, Green K, Reddon JR: An evaluation of the psychache scale on an offender population. Suicide Life-Threat 2005, 35:570-580.

63 Mee S, Bunney BG, Bunney WE, Hetrick W, Potkin SG, Reist C: Assessment of psychological pain in major depressive episodes. J Psychiatr Res 2011;45:1504-1510.

-64 Büchi S, Sensky T, Sharpe L, Timberlake N: Graphic representation of illness: a novel method of measuring patients' perceptions of the impact of illness. Psychother Psychosom 1998;67:222-225.
65 Büchi S, Buddeberg C, Klaghofer R, Russi EW, Brandli O, Schlosser C, Stoll T, Villiger PM, Sensky T: Preliminary validation of PRISM (Pictorial Representation of Illness and Self Measure) - A brief method to assess suffering. Psychother Psychosom 2002;71: 333-341.

66 Büchi S, Sensky T: PRISM: Pictorial Representation of Illness and Self Measure. A brief nonverbal measure of illness impact and therapeutic aid in psychosomatic medicine. Psychosomatics 1999;40:314-320.

67 Fava GA, Tomba E, Sonino N: Clinimetrics: the science of clinical measurements. Int J Clin Pract 2012;66:11-15.

68 Tomba E, Bech P: Clinimetrics and clinical psychometrics. Psychother Psychosom 2012; 81:333-343.

69 Guidi J, Fava GA, Bech P, Paykel E: The clinical interview for depression. Psychother Psychosom 2011;80:10-27.

70 Bech P: Mood and anxiety in the medically ill. Adv Psychosom Med 2012;32:118-132.
71 RyffCD: Challenges and opportunities at the interface of aging, personality and well-being; in John OP, Robins RW, Pervin LA (eds): Handbook of Personality: Theory and Research. New York, Guilford Press 2008, pp 399-418.

72 Fava GA, Tomba E: Increasing psychological well-being and resilience by psychotherapeutic methods. J Pers 2009;77:1903-1934.

73 Engel GL: Psychogenic pain and pain-prone patient. Am J Med 1959;26:899-918.

74 Eisenberger NI, Lieberman MD, Williams KD: Does rejection hurt? An fMRI study of social exclusion. Science 2003;302:290-292.

75 Schmahl C, Bohus M, Esposito F, Treede RD, Di Salle F, Greffrath W, Ludaescher P, Jochims A, Lieb K, Scheffler K, Hennig J, Seifritz E: Neural correlates of antinociception in borderline personality disorder. Arch Gen Psychiatry 2006;63:659-667.

76 Fava GA: Clinical judgment in psychiatry: requiem or reveille? Nord J Psychiatry 2012, E-pub ahead of print. 